Note

\title{
Expression in Escherichia coli, Refolding, and Purification of the Recombinant Mature Form of Human Matrix Metalloproteinase 7 (MMP-7)
}

\author{
Yuko Muta, ${ }^{1}$ Natsuki Yasui, ${ }^{1}$ Yoshiki Matsumiya, ${ }^{2}$ Motoki Kubo, ${ }^{2}$ and Kuniyo Inouye ${ }^{1, \dagger}$ \\ ${ }^{1}$ Division of Food Science and Biotechnology, Graduate School of Agriculture, Kyoto University, \\ Sakyo-ku, Kyoto 606-8502, Japan \\ ${ }^{2}$ Department of Biotechnology, College of Life Sciences, Ritsumeikan University, \\ Nojihigashi, Kusatsu, Shiga 525-8577, Japan
}

Received July 27, 2010; Accepted September 10, 2010; Online Publication, December 7, 2010

[doi:10.1271/bbb.100537]

In the latent pro-form of matrix metalloproteinase 7 (MMP-7), the cysteine residue in the pro-peptide binds the active-site zinc ion. Hence, recombinant active MMP-7 was prepared from pro-MMP-7 by modification of this cysteine residue with a mercuric reagent. In this study, mature MMP-7 was expressed in Escherichia coli as inclusion bodies, solubilized, and refolded with $1 \mathrm{M}$ L-arginine. The purified product was indistinguishable from the one prepared from pro-MMP-7 as assessed by hydrolysis of (7-methoxycoumarin-4-yl)acetyl-L-ProL-Leu-Gly-L-Leu-[ $N^{3}$-(2,4-dinitrophenyl)-L-2,3-diaminopropionyl]-L-Ala-L-Arg- $\mathrm{NH}_{2}$.

Key words: arginine; Escherichia coli; metalloproteinase; matrix metalloproteinase (MMP)-7; refolding

Human matrix metalloproteinase 7 (MMP-7, matrilysin) [EC 3.4.24.23] is the smallest matrix metalloproteinase (MMP). It lacks the carboxy-terminal hemopexinlike domain conserved in common MMPs. It is believed to play an important role in tumor invasion and metastasis. ${ }^{1,2)}$ It contains a zinc ion essential for activity and other zinc and calcium ions that are considered necessary for stability. ${ }^{3)}$ Like all other MMPs, it has the consensus sequence HEXXHXXGXXH, in which three histidine residues chelate an active-site zinc ion, and a methionine-containing turn (Met-turn). It exhibits a broad bell-shaped $\mathrm{pH}$-dependence with $\mathrm{p} K_{\mathrm{e}}$ values of about 4 and 10 , indicating that at least two ionizable groups are involved in the catalytic mechanism. ${ }^{4-7)}$

An efficient production method for recombinant human MMP-7 is necessary for basic study of this enzyme and the development of inhibitors. MMP-7 is synthesized as an inactive preproenzyme (267 amino acid residues) including 17 residues in the pre-peptide and 77 residues in the pro-peptide. The pro-peptide domain contains a single cysteine residue (Cys70), which binds the active-site zinc ion and renders proMMP-7 inactive. This mechanism is called the cysteineswitch mechanism of activation. ${ }^{8)}$ Under physiological conditions, the pro-form $(28 \mathrm{kDa})$ is activated into the mature form $(19 \mathrm{kDa})$ automatically by cleavage of the peptide bond linking Glu77 and Tyr78 (the numbering of amino acid residues of pro-MMP-7 is applied to mature MMP-7 beginning at the N-terminal Tyr78). In the production of recombinant MMP-7, pro-MMP-7 is expressed in $E$. coli as inclusion bodies, solubilized, and refolded. Refolded pro-MMP-7 is then converted to mature MMP-7 by modification of Cys70 with a mercuric reagent, such as $p$-aminophenylmercuric acetate. ${ }^{9,10)}$ The drawback of this method is that mercuric reagent is dangerous and their disposal is strictly regulated.

Generally, the pro-domain of protease acts as a molecular chaperone, and is sometimes necessary to produce a recombinant catalytically active enzyme. Both pro- and mature forms of MMPs are expressed in $E$. coli for this purpose. ${ }^{11)}$ Cha et al. expressed mature human MMP-7 in E. coli as inclusion bodies, from which the recombinant protein was solubilized with $4 \mathrm{M}$ guanidine $\mathrm{HCl}$ and refolded by dialysis to remove guanidine $\mathrm{HCl}$, but the activity $\left(k_{\text {cat }} / K_{\mathrm{m}}\right)$ of this product was about $50 \%$ of that of the one produced from pro-MMP-7. ${ }^{6)}$ We have reported that of various additives, arginine is the most effective at suppressing protein aggregation during the refolding process of pro-MMP-7. ${ }^{10)}$ Today, arginine is widely used in the refolding of proteins. ${ }^{12,13)}$ This is explained by its affinity for the aromatic groups present in proteins. ${ }^{13)}$ In this study, we used arginine in the refolding process of mature MMP-7 expressed in E. coli.

The expression plasmid for mature MMP-7 (pETMMP-7) was constructed by the insertion of amplified MMP-7 DNA into the NdeI and EcoRI sites of pET$22 \mathrm{~b}(+)$ (Merck, Tokyo). As shown in Fig. 1A, pETMMP-7 contains initiator codon ATG followed by a DNA sequence encoding the mature sequence (Tyr78Lys250) and stop codon TAG. BL21(DE3) cells were transformed with pET-MMP-7. Ampicillin was used at $50 \mu \mathrm{g} / \mathrm{ml}$. For seed culture, $2 \mathrm{ml}$ of $\mathrm{L}$ broth was inoculated with glycerol stock of the transformants and

$\dagger$ To whom correspondence should be addressed. Tel: +81-75-753-6266; Fax: +81-75-753-6265; E-mail: inouye@kais.kyoto-u.ac.jp

Abbreviations: AMPSO, 3-[(1,1-dimethyl-2-hydroxy-ethyl) amino]-2-hydroxypropane sulfonic acid; DMSO, dimethyl sulfoxide; HEPES, 2-[4-(2hydroxyethyl)-1-piperazinyl] ethanesulfonic acid; $K_{\mathrm{e}}$, proton dissociation constant; MES, 2-( $N$-morpholino)ethanesulfonic acid; MMP, matrix metalloproteinase; MOCAc-PLG, (7-methoxycoumarin-4-yl)acetyl-L-Pro-L-Leu-Gly; MOCAc-PLGL(Dpa)AR, (7-methoxycoumarin-4-yl)acetyl-LPro-L-Leu-Gly-L-Leu-[ $N^{3}$-(2,4-dinitrophenyl)-L-2,3-diaminopropionyl]-L-Ala-L-Arg- $\mathrm{NH}_{2}$ 
A

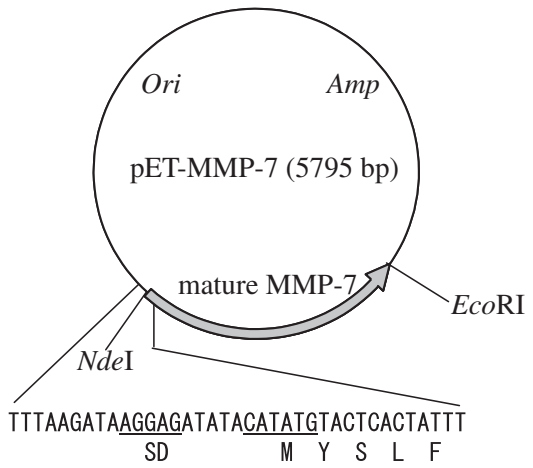

B

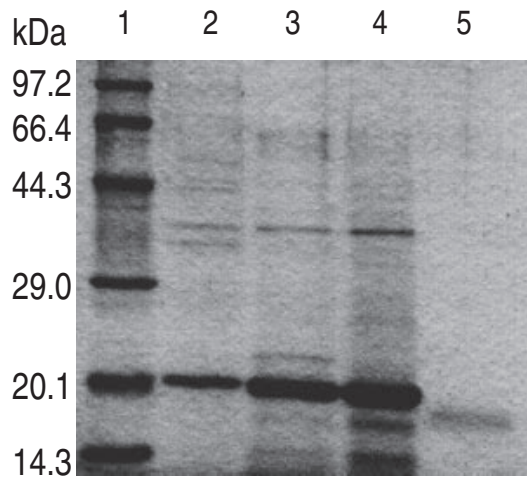

Fig. 1. Preparation of Recombinant Mature MMP-7.

A, Structure of pET-MMP-7. SD indicates the Shine-Dalgarno sequence. The NdeI site is underlined. B, Commassie Brilliant Bluestained $12.5 \%$ SDS-polyacrylamide gel showing marker proteins (lane 1), inclusion bodies (lane 2), the centrifuged supernatant after fractionation by ammonium sulfate at $20 \%$ saturation (lane 3 ), the centrifuged pellet after fractionation by ammonium sulfate at $60 \%$ saturation (lane 4), and active fractions of heparin affinity chromatography, which was purified MMP-7 (lane 5). Molecular mass marker kit was purchased from Takara Bio (Ohtsu, Japan).

grown with shaking at $37^{\circ} \mathrm{C}$ for $8 \mathrm{~h}$. The culture was then diluted 1:100 in $200 \mathrm{ml}$ of $\mathrm{L}$ broth and grown with shaking. After IPTG induction, growth was continued for $16 \mathrm{~h}$. The cells were harvested by centrifugation $(5,000 \times g, 30 \mathrm{~min})$, and suspended with $1 \mathrm{M}$ sucrose. After centrifugation, the pellet was suspended with $10 \mathrm{ml}$ of $20 \mathrm{~mm}$ Tris- $\mathrm{HCl}$ (pH 7.5), $200 \mathrm{~mm} \mathrm{NaCl}, 10 \%$ sucrose, $1 \mathrm{~mm}$ EDTA, and $0.5 \%$ Triton X-100. This step was repeated once. After centrifugation, the pellet was suspended with $20 \mathrm{ml}$ of $50 \mathrm{~mm}$ Tris- $\mathrm{HCl}$ ( $\mathrm{pH} 7.5), 150$ $\mathrm{mm} \mathrm{NaCl}, 1 \mathrm{~mm}$ EDTA, $0.5 \mathrm{~mm}$ PMSF, and $0.1 \mathrm{mg} / \mathrm{ml}$ lysozyme, and disrupted by sonication. The lysate was centrifuged $(10,000 \times g, 30 \mathrm{~min})$ and the pellet was collected. The inclusion body preparation thus obtained was solubilized with 10-20 volumes of $0.1 \mathrm{M}$ Tris- $\mathrm{HCl}$, $6 \mathrm{M}$ guanidine $\mathrm{HCl}$, and $0.1 \mathrm{M}$ DTT at $\mathrm{pH} 7.5$ with stirring overnight at $25^{\circ} \mathrm{C}$. The solution was diluted with 100 volumes of refolding buffer $(50 \mathrm{~mm}$ Tris- $\mathrm{HCl}$, $10 \mathrm{~mm} \mathrm{CaCl}_{2}, 0.1 \mathrm{~mm} \mathrm{Zn}\left(\mathrm{CH}_{3} \mathrm{COO}\right)_{2}$, and $1.0 \mathrm{M} \mathrm{L}-$ arginine at $\mathrm{pH} 7.5$ ), and left for $4 \mathrm{~h}$ at $4{ }^{\circ} \mathrm{C}$. MMP-7 activity hydrolyzing MOCAc-PLGL(Dpa)AR was detected in this diluted solution, indicating that MMP-7 was refolded from inclusion bodies. When refolding buffer without L-arginine was used, no activity was detected (data not shown). Saturated ammonium sulfate solution was added to the refolded solution to a final concentration of $20 \%$ saturation. After centrifugation, solid ammonium sulfate was added to the supernatant to a final concentration of $60 \%$ saturation. After centrifugation, the pellet was dissolved in $50 \mathrm{mM}$ HEPES buffer (pH 7.5), $10 \mathrm{mM} \mathrm{CaCl}_{2}$, and $0.05 \% \mathrm{v} / \mathrm{v}$ Brij-35 (buffer A) at $4{ }^{\circ} \mathrm{C}$, and dialyzed against the same buffer. The solution was applied to the column $(10 \mathrm{~mm}$ inner diameter $\times 45 \mathrm{~mm}$ ) packed with a heparin agarose (Sigma, St. Louis, MO) equilibrated with buffer A. The fractions containing MMP-7 were eluted with buffer A, containing $1.0 \mathrm{M} \mathrm{NaCl}$, and collected. The MMP-7 concentration was determined spectrophotometrically using a molar absorption coefficient at $280 \mathrm{~nm}, \varepsilon_{280}$, of $31,800 \mathrm{M}^{-1} \mathrm{~cm}^{-1}$.) Starting with $100 \mathrm{ml}$ of culture, about $2 \mathrm{mg}$ of purified MMP-7 was recovered. On SDS-PAGE under reducing conditions, the MMP-7 preparation thus obtained yielded a single band with a molecular mass of $19 \mathrm{kDa}$ (Fig. 1B). $\mathrm{NH}_{2}$-terminal sequence determination by Edman degradation revealed that it lacked the expected three $\mathrm{N}$-terminal amino acid residues, Met-Tyr-Ser, which is coincident with a previous report by Cha et al. ${ }^{6)}$ that denatured MMP-7 during the refolding process had the expected $\mathrm{N}$ terminal sequence of Met-Tyr-Ser-Leu-Phe, while the correctly refolded one lacked three N-terminal amino acids, Met-Tyr-Ser. It is thought that Met-Tyr-Ser was cleaved during the purification process.

The $\mathrm{pH}$-activity profiles as between the MMP-7 produced by the present method and that produced from pro-MMP-7 ${ }^{10)}$ were compared. MOCAc-PLGL(Dpa)AR (lot 491214) and MOCAc-PLG (lot 510913) were purchased from the Peptide Institute (Osaka). Their concentrations were determined using $\varepsilon_{410}=7.5$ $\mathrm{mM}^{-1} \mathrm{~cm}^{-1}$ and $\varepsilon_{324}=12.9 \mathrm{~mm}^{-1} \mathrm{~cm}^{-1}$ respectively. ${ }^{14)}$ The reaction was performed at $25^{\circ} \mathrm{C}$ by mixing $1,222 \mu \mathrm{l}$ of the reaction buffer, $20 \mu \mathrm{l}$ of the enzyme solution, and $8 \mu \mathrm{l}$ of $234 \mu \mathrm{M}$ MOCAc-PLGL(Dpa)AR dissolved in DMSO. The reaction buffers were $50 \mathrm{~mm}$ acetate- $\mathrm{NaOH}$ buffer at $\mathrm{pH} 3.6-5.8,50 \mathrm{mM}$ MES-NaOH buffer at $\mathrm{pH}$ 5.6-7.0, $50 \mathrm{~mm}$ HEPES-NaOH buffer at $\mathrm{pH} 6.8-$ 8.6, and $50 \mathrm{~mm}$ AMPSO-NaOH buffer at $\mathrm{pH}$ 8.6-10.4, each containing $10 \mathrm{mM} \mathrm{CaCl}_{2}$. The reaction was measured by following the increase in the fluorescence intensity at $393 \mathrm{~nm}$ with excitation at $328 \mathrm{~nm}$ with a JASCO FP-777 fluorescence spectrophotometer (Tokyo). The peptide bond of the Gly-L-Leu residues was cleaved by MMP-7, and the amount of the product, MOCAcPLG, was estimated by the fluorescence intensity in comparison with the fluorescence intensity of an authentic MOCAc-PLG solution. Hydrolysis was carried out under pseudo first-order conditions, where the initial concentration of MOCAc-PLGL(Dpa)AR (1.5 $\mathrm{M})$ was much lower than $K_{\mathrm{m}}(60 \mu \mathrm{M}) .{ }^{15)}$ The Michaelis-Menten equation was expressed as $v_{\mathrm{o}}=\left(k_{\mathrm{cat}} / K_{\mathrm{m}}\right)[\mathrm{E}]_{\mathrm{o}}[\mathrm{S}]_{\mathrm{o}}$, where $v_{\mathrm{o}}, k_{\text {cat }},[\mathrm{E}]_{\mathrm{o}}$, and $[\mathrm{S}]_{\mathrm{o}}$ are the initial reaction rate, the molecular activity, the initial enzyme concentration, and the initial substrate concentration respectively. The kinetic parameters, the intrinsic $k_{\text {cat }} / K_{\mathrm{m}},\left[\left(k_{\mathrm{cat}} / K_{\mathrm{m}}\right)_{\mathrm{o}}\right]$, and the proton dissociation constants $\left(K_{\mathrm{e} 1}\right.$ and $\left.K_{\mathrm{e} 2}\right)$ for the $\mathrm{pH}$-dependence of the activity were calculated from Eq. (1) by the non-linear least squares regression method with Kaleida Graph Version 3.5 (Synergy Software, Essex, VT):

$\left(k_{\text {cat }} / K_{\mathrm{m}}\right)_{\mathrm{obs}}=\left(k_{\text {cat }} / K_{\mathrm{m}}\right)_{\mathrm{o}} /\left\{1+\left([\mathrm{H}] / K_{\mathrm{e} 1}\right)+\left(K_{\mathrm{e} 2} /[\mathrm{H}]\right)\right\}$ 


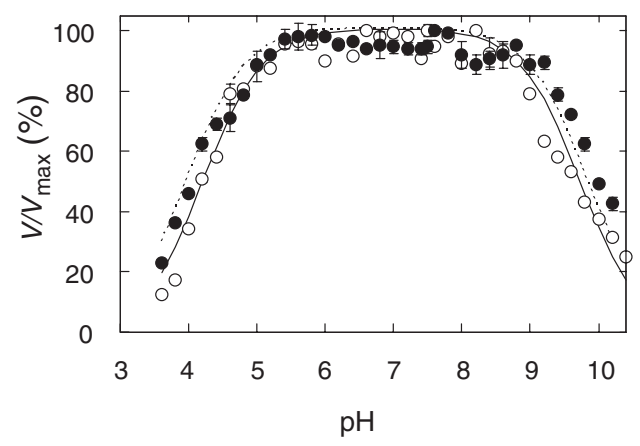

Fig. 2. Effect of $\mathrm{pH}$ on the MMP-7-Catalyzed Hydrolysis of MOCAc-PLGL(Dpa)AR at $25^{\circ} \mathrm{C}$.

The initial enzyme and substrate concentrations were $11.4 \mathrm{~nm}$ and $1.5 \mu \mathrm{M}$ respectively for the MMP-7 produced by the present method (open circle) and $6.3 \mathrm{nM}$ and $1.5 \mu \mathrm{M}$ respectively for the one produced from pro-MMP-7 (closed circle). The $v_{\max }$ values, which are the reaction rates at optimal $\mathrm{pH}$ levels, were $2.1 \mathrm{~nm} / \mathrm{s}$ at $\mathrm{pH} 7.5$ for the former MMP-7 and $1.5 \mathrm{nM} / \mathrm{s}$ at $\mathrm{pH} 7.5$ for the latter. Solid and broken lines represent the best fit to Eq. (1).

In this equation, $\left[\left(k_{\text {cat }} / K_{\mathrm{m}}\right)_{\text {obs }}\right]$ and $[\mathrm{H}]$ are the $k_{\text {cat }} / K_{\mathrm{m}}$ value observed and the proton concentration respectively at the specified $\mathrm{pH}$. As shown in Fig. 2, the $\mathrm{pH}$ dependences of the MMP-7 produced by this method and the one produced from pro-MMP-7 were similar. The $\left[\left(k_{\mathrm{cat}} / K_{\mathrm{m}}\right)_{\mathrm{o}}\right], \mathrm{p} K_{\mathrm{e} 1}$, and $\mathrm{p} K_{\mathrm{e} 2}$ values of the MMP-7 produced by the present method were $(1.20 \pm 0.01) \times$ $10^{5} \mathrm{M}^{-1} \mathrm{~s}^{-1}, \quad 4.2 \pm 0.0$, and $9.7 \pm 0.0$ respectively, and those of that produced from pro-MMP-7 were $(1.54 \pm 0.01) \times 10^{5} \mathrm{M}^{-1} \mathrm{~s}^{-1}, \quad 4.0 \pm 0.0$, and $9.8 \pm 0.0$ respectively.

We and others have reported the catalytic mechanism of MMP-7, ${ }^{4-7)}$ inhibition of MMP-7 activity by alcohols, ${ }^{15)}$ green tea catechins, ${ }^{16)}$ and lignans, ${ }^{17)}$ and the activation of MMP-7 activity by neutral salts. ${ }^{18)}$ The present production method is useful for site-directed mutagenesis experiments on MMP-7, which is currently under way to clarify the mechanisms. The present results also suggest the usefulness of L-arginine as an additive in the refolding process of proteins, which is done by trial and errors in most cases.

\section{Acknowledgments}

This study was supported in part by Grants-in-Aid for Scientific Research (nos. 17380065 and 20380061, to K. I.) from the Japan Society for the Promotion of Science.

\section{References}

1) Woessner JFJr and Taplin CJ, J. Biol. Chem., 263, 16918-16925 (1988).

2) Nagase H and Woessner JFJr, J. Biol. Chem., 274, 21491-21494 (1999).

3) Browner MF, Smith WW, and Castelhano AL, Biochemistry, 34, 6602-6610 (1995).

4) Oneda H and Inouye K, J. Biochem., 129, 429-435 (2001).

5) Muta Y, Oneda H, and Inouye K, Biochem. J., 386, 263-270 (2005).

6) Cha J, Pedersen MV, and Auld DS, Biochemistry, 35, 1583115838 (1996).

7) Cha J and Auld DS, Biochemistry, 36, 16019-16024 (1997).

8) van Wart HE and Birkedal-Hansen H, Proc. Natl. Acad. Sci. USA, 87, 5578-5582 (1990).

9) Kihira Y, Mori K, Miyazaki K, and Matuo Y, Urol. Oncol., 2, 20-26 (1996)

10) Oneda H and Inouye K, J. Biochem., 126, 905-911 (1999).

11) Windsor LJ and Steele DL, Methods Mol. Biol., 622, 67-81 (2010).

12) Takahashi $\mathrm{S}$, Ogasawara $\mathrm{H}$, Watanabe $\mathrm{T}$, Kumagai M, Inoue $\mathrm{H}$, and Hori K, Biosci. Biotechnol. Biochem., 70, 2913-2918 (2006).

13) Hirano A, Tokunaga H, Tokunaga M, Arakawa T, and Shiraki K, Arch. Biochem. Biophys., 497, 90-96 (2010).

14) Knight CG, Willenbrock F, and Murphy G, FEBS Lett., 296, 263-266 (1992).

15) Muta Y, Oneda H, and Inouye K, Biosci. Biotechnol. Biochem., 68, 2649-2652 (2004).

16) Oneda $H$, Shiihara $M$, and Inouye $K$, J. Biochem., 133, 571-576 (2003).

17) Muta $Y$, Oyama $S$, Umezawa $T$, Shimada $M$, and Inouye $K$, J. Agric. Food Chem., 52, 5888-5894 (2004).

18) Oneda H and Inouye K, J. Biochem., 128, 785-791 (2000). 